\title{
Respiratory tract disease and obstructive azoospermia
}

\author{
E NEVILLE, RAL BREWIS, WK YEATES, A BURRIDGE
}

From the Departments of Medicine, Urology, and Radiology, Royal Victoria Infirmary and Freeman Hospital, Newcastle upon Tyne

ABSTRACT Male infertility may be linked to respiratory tract disease in conditions such as cystic fibrosis and Kartagener's syndrome. Young's syndrome constitutes another such link, in which bronchiectasis is found in association with obstructive azoospermia and normal testicular function. We have studied 34 infertile men with mechanical azoospermia and appropriate control subjects to assess the number of patients with respiratory tract disease and the type and frequency of such disorders. Nineteen patients $(59 \%)$ had grossly abnormal sinus radiographs compared with six controls $(18 \%)(\mathrm{p}<0.01)$ and $19(56 \%-\mathrm{NS})$ gave a history of sinusitis; of these, six $(18 \%)$ had had sinus operations $(p<0.01)$. Eleven patients $(32 \%)$ had histories of repeated otitis media, of whom two had had mastoid operations. Twelve $(35 \%)$ had chronic bronchitis, of whom three were non-smokers. Ten other patients had bronchiectasis $(p<0.001)$ and three of these had had a lobectomy. The chest radiograph was abnormal in 18 patients $(\mathrm{p}<0.001)$, including all 10 with bronchiectasis. Two patients had severe airflow obstruction and 13 others had a mildly obstructive pattern. This controlled study confirms that a significant excess of sinorespiratory disease can be identified in young men with obstructive azoospermia. We have found no features in the history or in the results of examination or investigations to explain why some of these patients have respiratory tract disease while others do not.

There are well established links between male infertility and chronic respiratory tract disease in patients with cystic fibrosis and the primary ciliary dyskinesia syndrome (also known as the immotile cilia or Kartagener's syndrome). In cystic fibrosis there is a generalised metabolic defect leading to bronchiectasis, pancreatic insufficiency, and male infertility ${ }^{1}$ while in the latter syndrome an abnormality of motility of the tails of spermatozoa is shared by cilia of the respiratory tract, leading to chest and sinus infections. $^{2}$

Young ${ }^{3}$ described a group of men who presented with primary infertility who had normal spermatozoa in the epididymides and yet none in the ejaculate (obstructive azoospermia); $54 \%$ of these patients had had severe chest disease in childhood.

No previous report has described the clinical details of the respiratory disease in patients with obstructive azoospermia. In this study we have examined a group of such patients to determine the prevalence, nature, and severity of respiratory tract

Address for reprint requests: Dr E Neville, St Mary's Hospital, Milton Road, Portsmouth PO3 6AD.

Accepted 9 August 1983 disease and to identify any common antecedent history.

\section{Methods}

All patients had been referred with either obstructive azoospermia or primary infertility with subsequent confirmation of obstructive azoospermia. Sixty nine patients were identified and subsequently approached with their general practitioner's permission. Thirty four attended; of the remainder, 15 had left the area, three declined to attend, and 17 did not reply to two separate letters. All patients who attended gave informed consent to the study, which was approved by the local ethical committee.

On attendance each patient underwent a clinical interview and physical examination, and a questionnaire was completed by one of us. Spirometry was performed with a Vitalograph bellows spirometer and single breath transfer factor (TLCO) was measured with a Morgan Resparameter (Mark IV). Transfer coefficient (KCO) was calculated ${ }^{4}$ and normal values were taken from Cotes. ${ }^{5}$ Sputum was inspected and cultured and blood was taken for obtaining the white cell count and differential, determining immunoglobulin concentrations, and 
looking for organ specific and non-specific autoantibodies and aspergillus and avian precipitins. Sweat chloride concentration was estimated by pilocarpine iontophoresis. Chest and nasal sinus radiographs were obtained.

Thirty four young men working in the hospital, matched for age and smoking habits, were interviewed and the same questionnaire was used, though no examination or investigations were performed on these controls. Chest radiographs were compared with pre-employment films of young male hospital personnel, while control sinus radiographs were obtained by taking an occipitofrontal film of the sinuses of young male patients who attended the accident and emergency department needing a skull radiograph-usually on account of a head injury. Both groups of radiographs were randomised and read blindly by one observer. Differences between groups were assessed by the $\chi^{2}$ test with Yates's correction.

\section{Results}

The ages of the 34 patients ranged from 23 to 53 (mean 35) years. The duration of proved infertility ranged from three to 17 (mean nine) years. All the patients had been previously investigated and found to have azoospermia with otherwise normal semen. Follicle stimulating hormone and luteinising hormone were each minimally elevated in two (different) patients but these were normal when repeated. Serum testosterone was normal in all 13 patients in whom it was estimated. Testicular biopsy had been performed in 26 cases and the findings were normal in $23(88 \%)$ but slight reduction of spermatogenesis was found in the other three patients. The heads of the epididymides were palpably enlarged in all the patients. The eight patients who did not have a testicular biopsy had the same clinical picture, with azoospermia, normal sized gonads, and distended epididymal heads.

Sixteen $(47 \%)$ of the patients were smokers. These smokers gave a history of from two to 70 (mean 18) pack years of cigarette consumption. All patients were normally developed with heights of 1.58-1.93 (mean 1.71) $\mathrm{m}$ and their occupations covered the whole social range.

There was a clear excess of respiratory symptoms in the patients compared with the control subjects (table 1). Two of the patients and one of the controls were under treatment for asthma and three other patients had variable symptoms compatible with asthma. One third of the patients admitted to regular dyspnoea but this was usually during moderate effort (climbing stairs and hills). Only one patient was dyspnoeic walking with contemporaries on the
Table 1 Clinical history of 34 patients with obstructive azoospermia and 34 control subjects

\begin{tabular}{|c|c|c|c|c|}
\hline & \multicolumn{2}{|c|}{ No (\%) of patients } & \multicolumn{2}{|c|}{ No (\%) of controls } \\
\hline & Total & $\begin{array}{l}\text { Non- } \\
\text { smokers }\end{array}$ & Total & $\begin{array}{l}\text { Non- } \\
\text { smokers }\end{array}$ \\
\hline Total group & $34(100)$ & $18(53)$ & $34(100)$ & $18(53)$ \\
\hline Current dyspnoea & $11(32)$ & 4(22) & $1(3) \dagger$ & $0(0)$ \\
\hline Daily cough & $24(71)$ & $11(61)$ & $4(12) \ddagger$ & $0(0)$ \\
\hline $\begin{array}{l}\text { Daily cough before } \\
\text { age } 15\end{array}$ & $13(38)$ & $8(44)$ & $1(3) \ddagger$ & $0(0)^{*}$ \\
\hline $\begin{array}{l}\text { Sputum green at } \\
\text { any time }\end{array}$ & $18(53)$ & $8(44)$ & $1(3) \neq$ & $0(0)^{*}$ \\
\hline Sputum $\geqslant 30 \mathrm{ml} /$ day & $9(26)$ & $1(6)$ & $1(3) \ddagger$ & $0(0)^{*}$ \\
\hline
\end{tabular}

Table 2 Past medical histories of 34 patients with obstructive azoospermia and 34 control subjects

\begin{tabular}{lcc}
\hline & $\begin{array}{l}\text { No (\%) of } \\
\text { patients }\end{array}$ & $\begin{array}{l}\text { No (\%) of } \\
\text { controls }\end{array}$ \\
\hline Sinusitis & $19(56)$ & $15(44)$ \\
Sinus operation & $6(18)$ & $0(0) \dagger$ \\
Otitis & $11(32)$ & $6(17)$ \\
Ear operation & $2(6)$ & 0 \\
Postural Drainage advised & $4(12)$ & $0^{*}$ \\
Previous bronchogram & $4(12)$ & $0^{*}$ \\
Lobectomy & $3(9)$ & 0 \\
Family history of asthma & $5(15)$ & $5(15)$ \\
Measles & $23(68)$ & $24(71)$ \\
Pneumonia & $9(26)$ & $4(12)$ \\
Pertussis & $5(15)$ & $5(15)$ \\
\hline
\end{tabular}

${ }^{*} p<0.05 ; \dagger p<0.01$.

level. Nearly three quarters of the patients had a daily cough, including 11 who were non-smokers. Most strikingly, 13 of the patients, including eight lifetime non-smokers, remembered having a regular cough before the age of 15 . Despite the match for smoking history, only four controls admitted to a regular cough and one of these, the one with asthma, had had the cough before the age of 15 . Among the patients there were nine with a history of increased sputum production (26\%) and 18 with episodes of green sputum (53\%) but only one control had such a history-a highly significant difference.

Details of the past medical histories of patients and controls appear in table 2. Over half of the patients had had sinusitis but $44 \%$ of the controls had a similar history. Many of the patients volunteered the information that their sinusitis was a serious recurrent problem. As this had not been anticipated, it was not assessed in a systematic manner. The importance of this feature was, however, emphasised by the observation that six $(18 \%)$ of the patients but none of the controls had had operations on their sinuses. A third of the patients had had otitis and two patients had had mastoid operations but these figures were not significantly different from those of the controls. Four patients had been advised to use postural drainage in childhood and 
Table 3 Nasal sinus radiographs in 34 patients with obstructive azoospermia and 34 controls who had skull radiographs on account of head injury

\begin{tabular}{lcl}
\hline & $\begin{array}{c}\text { No (\%) of } \\
\text { patients }\end{array}$ & $\begin{array}{l}\text { No (\%) of } \\
\text { controls }\end{array}$ \\
\hline Normal & $2(6)$ & $14(41) \dagger$ \\
Mucosal thickening & $12(35)$ & $13(38)$ \\
Polypoid changes & $4(12)$ & $1(3)$ \\
Fluid levels & $5(15)$ & $3(9)^{*}$ \\
Opaque sinuses & $10(29)$ & $2(6)^{*}$ \\
\hline
\end{tabular}

${ }^{*} \mathrm{p}<0.05 ; \dagger \mathrm{p}<0.01$.

three had had a lobectomy for bronchiectasis.

Careful questioning failed to reveal any increased frequency of known antecedent causes of bronchiectasis such as measles, pneumonia, or pertussis (table 2). Two patients had been diagnosed as having sarcoidosis-one with previous pulmonary mottling, anterior uveitis, and sarcoid histological appearances on the mediastinal gland biopsy specimen and the other with bilateral hilar lymphadenopathy only. One patient had had pink disease in childhood.

Examination of the patients revealed few abnormalities: four (12\%) patients had basal crackles and three $(9 \%)$ had finger clubbing.

\section{RADIOLOGY}

Eighteen (53\%) patients had abnormal pulmonary changes evident on the chest radiographs whereas only one control subject showed a pulmonary abnormality $(p=0.001)$. Three patients showed evidence of a previous thoracotomy and eleven had areas of peribronchial thickening. Two further patients had areas of consolidation thought to be due to infection in a bronchiectatic segment. Three patients with peribronchial thickening had areas of cystic bronchiectasis. One of these had considerable changes, was asthmatic, and gave positive responses to serum precipitin and skinprick tests for Aspergillus fumigatus. One patient had basal linear shadowing thought to represent fibrosis. Of the two patients who had developed sarcoidosis since being investigated for infertility, only one had an abnormal chest radiograph and this showed bilateral hilar lymphadenopathy. Five (15\%) of the 34 control chest radiographs were assessed as abnormal; one had peribronchial thickening, two had minor skeletal abnormalities, and two had calcified hilar lymph nodes. Only one had a pulmonary radiological abnormality.

Bronchograms had been performed in the three patients who had undergone lobectomy; bronchography in one other patient had also showed bronchiectasis, which affected both lower lobes.

Radiographs of the maxillary and nasal sinuses showed abnormalities in $32(94 \%)$ of the patients and $20(59 \%)$ of the controls $(\mathrm{p}<0.01)$. Twelve $(35 \%)$ of the patients and $13(38 \%)$ of the controls had varying degrees of mucosal thickening. The patients included $19(56 \%)$ with more severe abnormalities (polyps, fluid levels, or total opacification of the sinuses) compared with only six $(18 \%)$ in the control group $(p<0.01$; table 3$)$.

\section{PULMONARY FUNCTION}

Spirometry showed airflow obstruction in $15(44 \%)$ patients. This was severe $\left(\mathrm{FEV}_{1} / \mathrm{VC}<50 \%\right.$ and FEV $133-48 \%$ predicted) in two patients, moderate (FEV 1 /VC 51-60\% and $\mathrm{FEV}, 50-60 \%$ predicted) in two, and mild (FEV /VC 61-74\%) in 11. An improvement in $\mathrm{FEV}_{1}$ after bronchodilator exceeding $15 \%$ was seen in two patients-one with severe and one with moderate airflow obstruction. TLCO and KCO were normal in all 34 patients.

\section{LABORATORY DATA}

Sputum was frankly purulent in two cases and mucopurulent in nine. Two specimens grew Pneumococcus, one Haemophilus infuenzae and one Pseudomonas aeruginosa (this was from the patient with asthma and aspergillosis). Six patients had leucocytosis and one mild leucopenia $\left(2.9 \times 10^{9} / 1\right)$. Abnormalities of immunoglobulins were found in 11 patients but there was no pattern to this; the IgG concentration was raised in five patients, the IgA in four, and the IgM in three (in only one case were concentrations of all three immunoglobulins raised); while the IgG concentration was low in two patients and the IgM in six. One patient had thyroid autoantibodies at a titre of $1 / 800$ and one was weakly positive for gastric parietal cell antibodies. No other autoantibodies were detected. Antibodies to avian antigens were found in two patients and aspergillus precipitins in the one asthmatic patient with aspergillosis. The highest value of sweat chloride was $43 \mathrm{mmol}(\mathrm{mEq}) / 1$ and only nine patients had a concentration higher than $30 \mathrm{mmol} / \mathrm{l}$; these values are normal in adults.

CLINICAL DIAGNOSIS OF RESPIRATORY DISEASE Ten patients (29\%) were diagnosed as having bronchiectasis. This diagnosis was based in four patients on bronchography that had led to lobectomy in three cases. All 10 patients diagnosed as having bronchiectasis had an abnormal chest radiograph compatible with the diagnosis (see above). Although all had a productive cough, in only three cases was the daily sputum volume $30 \mathrm{ml}$ or more. Eight reported episodic green coloration of sputum. Three patients had previously been advised to have postural drainage, three had auscultatory crackles, and three had finger clubbing. In addition to an abnor- 
mal chest radiograph, all patients had one or more of the above features.

Twelve other patients $(35 \%)$ were diagnosed as having chronic bronchitis by Medical Research Council criteria, of whom three were lifetime nonsmokers. Nineteen patients $(56 \%)$ had a history of recurrent sinusitis while $32(94 \%)$ had abnormal sinus radiographs. When all clinical, radiographic, and functional information was taken into account, only six patients (17\%) were found to be "normal."

\section{Discussion}

Young $^{3}$ reported that $10(19 \%)$ of his 52 patients had an antecedent diagnosis of bronchiectasis and Hendry et $a l^{6}$ described bronchiectasis in three $(10 \%)$ of 30 patients. We have been able to confirm this association of obstructive azoospermia with bronchiectasis, which on clinical and radiographical evidence was present in 10 patients $(29 \%)$. Young ${ }^{3}$ recorded 18 patients $(33 \%)$ with bronchitis, but did not mention sinusitis, while Hendry et $\mathrm{al}^{6}$ described seven $(23 \%)$ with bronchitis and five $(17 \%)$ with sinusitis without giving clinical details. We have also confirmed both of these clinical associations.

We have not been able to find any obvious aetiological relationship between respiratory tract disease and obstructive azoospermia. There was no common past history of any of the well known factors predisposing to the development of bronchiectasis. Equally there was no past history of venereal disease, which might have caused an inflammatory obstruction to the genital tract. On the other hand, this is an unusual group of young men for reasons other than the high frequency of bronchiectasis, bronchitis, and sinusitis. To find by chance two of 34 patients $(6 \%)$ with sarcoidosis in England, where the prevalence of sarcoidosis has been reported as 10-36 per 100000,7 is unlikely. Another patient was asthmatic and developed bronchiectasis with aspergillosis. This mechanism did not apply in any of the other patients, though there was evidence of reversibility of airflow obstruction in two instances.

Could this syndrome be a forme fruste of cystic fibrosis? This seems unlikely because of the differences in clinical picture and genital dysfunction. Although there may be a female equivalent of obstructive azoospermia this has not been recognised in association with respiratory tract disease. Cystic fibrosis is inherited as an autosomal recessive trait with equality of expression between the sexes. The bronchiectasis in cystic fibrosis leads to progressive respiratory failure and death and the lungs are characteristically colonised initially with Staphylococcus pyogenes and later with Ps aeruginosa. ${ }^{8}$ The lower respiratory tract disease that we have observed is less severe, generally nonprogressive, and associated with a low frequency of any positive microbiological culture. Hendry et $a l^{6}$ found normal results in sweat tests and normal pancreatic juice tryptic activity in their patients and we have also found normal values of sweat chloride. Patients with Young's syndrome have normal testicular function with seemingly normal spermatozoa in distended epididymal heads and obstructed vasa deferentia. In contrast, patients with cystic fibrosis have decreased spermatogenesis with abnormal sperm forms and frequently no vas deferens. ${ }^{9}$ Although it has been suggested that some patients with normal spermatogenesis and azoospermia may have variants of the cystic fibrosis syndrome, our patients did not fit into the categories suggested by Stern et al,${ }^{10}$ who found the obstructive azoospermia to be variably associated with absence of the vas deferens, a family history of cystic fibrosis, positive results in sweat tests, and chronic pseudomonas chest infections. For these reasons our patients with obstructive azoospermia are unlikely to have a subclinical form of cystic fibrosis.

Could obstructive azoospermia with respiratory tract disease be a form of the "primary ciliary dyskinesia syndrome"? Bronchiectasis, bronchitis, and sinusitis occur in both conditions but in some of the patients with immotile cilia there is also situs inversus. This did not occur in our patients. In the ciliary dyskinesia syndrome sperm counts in the ejaculate are normal but all the spermatozoa are non-motile. Electron microscopy of spermatic tails shows a consistent ultrastructural abnormality of the microtubules-absence of dynein arms. ${ }^{21}$ This abnormality is also found in cilia from the respiratory tract and results in delayed clearance of foreign particles from the lungs. ${ }^{11}$ Hendry and colleagues ${ }^{6}$ reported that in 10 patients with bronchiectasis or bronchitis and obstructive azoospermia electron microscopy showed a normal microtubular arrangement in epididymal and two bronchial specimens and dynein arms were present in all cases. Le Lannou and colleagues ${ }^{12}$ confirmed these findings in spermatozoa from the epididymal heads of their patients and also in three bronchial biopsy specimens. In a further report Hendry et $a l^{13}$ noted a few spermatozoa in the ejaculate of four patients after epididymovasostomies but sperm motility was poor or absent. Yeates, ${ }^{14}$ however, found that sperms aspirated from distended epididymal heads of patients with obstructive azoospermia were motile when examined immediately under a light microscope. Further evidence for normal ciliary activity in this syndrome was reported by Rutland, ${ }^{15}$ who observed normal nasal ciliary beat frequency in 11 such patients. 
The cause of the epididymal obstruction in Young's syndrome is not completely clear: although the vasa have been reported to be patent, they may also be obstructed by amorphous, acidic material with some cellular debris ${ }^{12}$ and Yeates reported inspissated spermatozoa filling the epididymal lumen. ${ }^{14}$

Other reports have listed the sinorespiratory association of obstructive azoospermia without commenting on the clinical or radiographic features. ${ }^{36} \mathrm{We}$ have concentrated on this aspect of the syndrome and, using control data, have confirmed the association of chronic sinusitis, bronchitis, and bronchiectasis with obstructive azoospermia. In common with other authors we are unable to offer an explanation either for the association or for the underlying pathogenetic mechanism.

We thank Miss Monica Goldfinch for performing the sweat tests, Miss Judith Purdon and Mrs Janet Johnson for performing the respiratory function tests, and Miss Veronica Downey for typing the manuscript.

\section{References}

' Shwachman H, Kowalski M, Khaw KT. Cystic fibrosis: a new outlook. 70 patients above 25 years of age. Medicine 1977;56:129-49.

${ }^{2}$ Eliasson R, Mossberg B, Camner P, Afzelius BA. The immotile cilia syndrome. A congenital ciliary abnormality as an etiologic factor in chronic airway infections and male sterility. N Engl J Med 1977;297:1-6.

${ }^{3}$ Young D. Surgical treatment of male infertility. $J$ Reproduct Fertil 1970;23:541-2.
${ }^{4}$ McGrath MW, Thomson ML. The effect of age, body size and lung volume change on alveolar-capillary permeability and diffusing capacity in man. $J$ Physiol 1959;146:572-82.

${ }^{5}$ Cotes JE. Lung function: assessment and application in medicine. 3rd ed. Oxford: Blackwell Scientific Publications, 1975.

${ }^{\circ}$ Hendry WF, Knight RK, Whitfield HN, et al. Obstructive azoospermia: respiratory function tests, electron microscopy, and the results of surgery. $\mathrm{Br} J \mathrm{Urol}$ 1978;50:598-604.

${ }^{7}$ Anderson R, Brett GZ, James DG, Siltzbach LE. The prevalence of intrathoracic sarcoidosis. Med Thorac 1963;20:152-6.

${ }^{8}$ Mitchell-Heggs P, Mearns M, Batten JC. Cystic fibrosis in adolescents and adults. $Q J$ Med 1976;45:479-504.

${ }^{9}$ Kaplan E, Shwachman H, Perlmutter AD, Rule A, Khaw K-T, Holsclaw DS. Reproductive failure in males with cystic fibrosis. $N$ Engl J Med 1968;279:65-9.

${ }^{10}$ Stern RC, Boat TF, Doershuk CF. Obstructive azoospermia as a diagnostic criterion for the cystic fibrosis syndrome. Lancet 1982;i:1401-4.

"Afzelius BA. The immotile-cilia syndrome and other ciliary diseases. Int Rev Exp Pathol 1979;19:1-43.

${ }^{12}$ Le Lannou D, Verger JP, Kernec J, Segalen J, Lescoat D, Lobel B. Structure de l'epithelium bronchique et epididymaire dans l'association infertile masculine et bronchiectasie (syndrome de Young). INSERM 1981;103:117-22.

${ }^{13}$ Hendry WF, Whitfield HN, Stansfield AG, et al. Defects in Young's syndrome and Kartagener's syndrome. Lancet 1978;ii: 1152.

14 Yeates WK. Azoospermia 1980. Acta Chir Iugoslav 1981 ;suppl 2:603-8.

15 Rutland J. In discussion after: Pavia D, Agnew JE, Bateman JRM, et al. Lung mucociliary clearance in patients with Young's syndrome. Chest 1981;80, suppl: 892-5. 